\title{
REDEFINING ROLES
}

The Professional, Faculty, and Graduate Consultant's Guide to Writing Centers

\author{
EDITED BY \\ MEGAN SWIHART JEWELL \\ JOSEPH CHEATLE
}


(C) 2021 by University Press of Colorado

Published by Utah State University Press

An imprint of University Press of Colorado

245 Century Circle, Suite 202

Louisville, Colorado 80027

All rights reserved

Manufactured in the United States of America

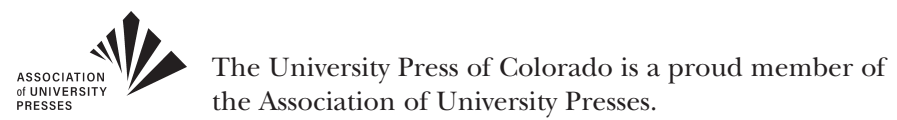

The University Press of Colorado is a cooperative publishing enterprise supported, in part, by Adams State University, Colorado State University, Fort Lewis College, Metropolitan State University of Denver, Regis University, University of Colorado, University of Northern Colorado, University of Wyoming, Utah State University, and Western Colorado University.

$\infty$ This paper meets the requirements of the ANSI/NISO Z39.48-1992 (Permanence of Paper).

ISBN: 978-1-64642-084-1 (paperback)

ISBN: 978-1-64642-085-8 (ebook)

https://doi.org/10.7330/9781646420858

Library of Congress Cataloging-in-Publication Data

Names: Jewell, Megan Swihart, editor. I Cheatle, Joseph, editor.

Title: Redefining roles : the professional, faculty, and graduate consultant's guide to writing centers / edited by Megan Swihart Jewell, Joseph Cheatle.

Description: Logan : Utah State University Press, [2020] I Includes bibliographical references and index.

Identifiers: LCCN 2021003982 (print) I LCCN 2021003983 (ebook) I ISBN 9781646420841 (paperback) I ISBN 9781646420858 (ebook)

Subjects: LCSH: Writing centers. I English language-Rhetoric-Study and teaching (Higher) I Academic writing-Study and teaching (Higher) I Tutors and tutoring-Vocational guidance. I Graduate teaching assistants-Vocational guidance. I English teachers-Vocational guidance.

Classification: LCC PE1404 .R3823 2020 (print) I LCC PE1404 (ebook) I DDC $808 / .0420711-\mathrm{dc} 23$

LC record available at https://lccn.loc.gov/2021003982

LC ebook record available at https://lccn.loc.gov/2021003983

The University Press of Colorado gratefully acknowledges the support of Iowa State University toward the publication of this volume.

Cover illustrations by Cat_arch_angel/Shutterstock. 


\section{CONTENTS}

Foreword

Elizabeth H. Boquet xi

Introduction

Joseph Cheatle and Megan Swihart Jewell 3

PART 1: FACULTY AND PROFESSIONAL CONSULTANTS

1. Redefining Training for Faculty Tutors: Practical Strategies for Creating Sustainable Professional Development

Miriam E. Laufer 17

2. Modular Training for Professional Writing Center Consultants Fallon N. Allison 31

3. Examining Assumptions about Training and Development for Writing Center Professional Consultants

Anne Shiell 44

4. Reading between the Lines: Professional Tutor Training with the Stanislavski System for Actors

Irina Ruppo 58

5. Professional Tutors, Shifting Identities: Narratives from the Center Kimberly Fahle Peck, Lisa Nicole Tyson, Amanda Gomez, and Steffani Dambruch 71

6. Teachers versus Tutors: Is There a Place for Faculty Tutors in a University Writing Center?

Arundhati Sanyal and Kelly A. Shea 86

7. Between Definitions: Negotiating the Role of Professional Writing Consultants Online

Matthew Sharkey-Smith 101 
8. Faculty and Professional Consultants, the Writing Center, and STEM Catherine Siemann

\section{PART 2: GRADUATE STUDENT CONSULTANTS}

9. When Is a Peer Not a Peer? Negotiating Authority and Expertise in Graduate Student Writing Consultations

Marcus Weakley and Mark Pedretti

10. Integrating Graduate Student Consultants: Community Building in Writing Centers through Onboarding and Mentorship

Genie Giaimo and Joseph Cheatle 139

11. Critical Mentorship in the Writing Center: Teaching Intentional Kindness and Rhetoric of Respect in Staff Education

Anna Sicari 152

12. Graduate Tutor Professional Development—and Collaborative Leadership_-in an Undergraduate Writing Center

Rebecca Nowacek, Matt Burchanoski, Danielle Clapham, Will Fitzsimmons, Alex Frissell, Lisa Lamson, and Anna Scanlon 165

13. (Graduate) Friends with Benefits: Writing Relationships into the Center Elise Dixon and Cassie J. Brownell 179

14. Making the Invisible Visible: Valuing Labor in the Design of an Observation-Based Mentor Program for Graduate Student Writing Tutors

$$
\text { Alex Wulff } 192
$$

15. Investing in Graduate Tutor Training: A Sustained Approach Vicki Behrens and Alex Funt 204

16. Disciplinary Ambassadors in the Graduate Writing Center: A Professional Development Framework for Graduate Consultants from Diverse Fields

Kristin Messuri 216 
17. Genre Knowledge and (Cross)Disciplinary Awareness: Preparing Graduate Consultants to Support Proposals

Elizabeth Festa $\quad 229$

18. An Inquiry-Based Approach for Customizing Training for Graduate Student Tutors

Megan Boeshart Burelle and Meagan Thompson

Index 253

About the Editors 263

About the Authors 265 


\title{
INTRODUCTION
}

\author{
Joseph Cheatle and Megan Swihart Jewell
}

The essays in this collection address the complexities involved in tutoring arrangements that do not fit neatly into the traditional undergraduate peer-to-peer model, which has been the primary focus in most training literature for writing center consultants. While building upon this established body of undergraduate consultant training resources, we hope to incorporate within the conversation training issues involving professional, faculty, and graduate consultants. We use the term "professional" to refer to writing center consultants who are not primarily teaching and who are not enrolled as graduate or undergraduate students; we consider professional consultants, as opposed to faculty, as those hired to work exclusively (or near exclusively) in the writing center. We use the term "faculty" to describe consultants whose primary responsibility is teaching and only work in writing centers as a secondary responsibility. And we use the term "graduate" consultants to refer to both those that are normally graduate assistants whose main instructional responsibility is to work in writing centers and those whose wages are not necessarily attached to an academic stipend, but who are enrolled in a graduate program. For our purposes, we have grouped the chapters on faculty and professional consultants together because, for the most part, they encounter similar dynamics in writing centers.

Our title, "Redefining Roles," is intended to open up a dialogue that accounts for and involves all levels of writing consultant training while more accurately reflecting the long-standing realities of center staffing. As Elizabeth Boquet notes in the foreword, many writing centers started out as faculty- or graduate-staffed centers. And, according to the 2016-17 report of the Writing Center Research Project at Purdue University, writing centers continue to be staffed by these populations in significant numbers. Of the 270 writing centers polled, 129 writing centers $(47.8 \%)$, indicated that they employed graduate consultants, while 17.4 percent indicated they employed faculty consultants, and 29.3 percent indicated they employed professional consultants (Writing Centers Research Project Survey n.d.). These numbers not only show that writing center consultants 
are composed of graduate, faculty, and other professionals, but they also reveal that nonundergraduate consultants make up a significant percentage of those who work in writing centers. The assumption in the lack of published training materials specifically written for nonundergraduate consultants is that this population, particularly those experienced in classroom teaching, do not need writing center-specific training: after all, they've instructed in classrooms, hold degrees, and therefore implicitly know how to consult. Yet, the essays in this collection illustrate the various ways that not only do such assumptions fail to account for the complex demands of individualized writing center instruction, but they also serve to weaken the strides taken over the past forty or more years to validate the intellectual work we undertake as writing center professionals working in challenging academic contexts. Our collection serves to make visible these consultants' efforts, to continue rescuing writing centers from the scholarly and institutional obscurity of error correction, itself a myth built upon a faulty and elitist premise, and to recognize the higher-order intellectual labor that we have long performed.

While we address how institutional status mediates one's writing center practices, the roles that consultants adopt from session to session are continually being redefined as part of the very nature of the position. In writing centers in particular, the roles continuously shift-and, indeed, institutional status adds another layer to an already complex instructional environment. Jackie Grutsch McKinney's (2013) book, Peripheral Visions for Writing Centers, is instructive here: McKinney charts the complex demands of writing center positions in terms of intellectual and emotional labor, noting the ever-changing higher-order, lower-order, intellectual, and emotional work required of consultants and directors (2013). On any given day, for example, she points out, an administrator or consultant may need to switch gears between answering questions about commas for a novice writer, to delivering instructional content to a large classroom of students, to tackling a higher-level organizational issue in a graduate-level thesis. In addition, writing center administrators and consultants, often composed of contingent faculty, must more than many other university employees deal with fluctuating work conditions, such as changes in offices and other scheduling or teaching demands unique to a more institutionally vulnerable staff. The importance of our collection lies in the fact that we are addressing and-most important—validating the complex and nuanced work that a significant number of writing center consultants perform while also acknowledging the ways in which institutional status mediates one's responses to the challenges of writing center positions. 
The impetus for this collection began more than fourteen years ago, when Megan began directing a writing center staffed mainly by writing faculty who were teaching first- and second-year writing courses across the university while working in the center as part of their overall instructional load. Early on, she began searching for resources on how to negotiate the complex interactions regarding teaching versus tutoring roles that accompanied this staffing arrangement. While the writing center that Megan directed was also staffed by humanities graduate students, mostly from the English Department, and while it later grew to include undergraduate peer consultants from all campus majors, most of its staff included PhD-holding instructors with years of classroom experience. Yet, as would be expected, even though many of the faculty had years of experience with the tutorial model of meeting one-on-one with students, a startling number of them had no formal writing center experience. At first, this lack of writing center experience among faculty consultants did not seem like a major area of concern: After all, these were well-credentialed scholars that the university was fortunate to have staffing its writing centers. Yet, while they proved to be skilled consultants, Megan found that addressing the complex needs of faculty in the specific context of a writing center was a challenge that required many forms of impromptu problem-solving and de facto policy-making. In terms of problem-solving, Megan, along with the faculty consultants, had to negotiate additional issues that, more or less, had to do with both a consultant's institutional status as well as the expectation that only undergraduates (primarily eighteen- to twenty-two-year-olds) staff centers. Some examples include

- What to do when a student comes in with a poorly written writing prompt written by a faculty colleague

- What to do when your own student books multiple appointments with you regarding your paper assignment

- What to do when more of your students have access to your writing center hours than others

- How to put students at ease who arrive at the writing center expecting a (younger) peer consultant and not a faculty member

- What to do when you see an undergraduate tutor being overly directive while working with a student

- What to do when you see a graduate student tutor incorrectly describing the role of the writing center to a student

These are only a few of the issues that are faced in many writing centers composed of a diverse body of consultants working in diverse fields 
in a challenging academic job market context; and center practices certainly have evolved thanks to the willingness of staff to engage in a collaborative approach to thoughtfully considering these issues. They have, over the years, worked through the tangled issues and ever-present specter of institutional authority, administrative demands, curriculum changes, and varying forms of oversight and assessment that are often, for faculty, at the center of such complex dynamics. They have learned to negotiate within the various level of student-teacher authority accompanying all levels of consultants, from professionals and faculty to graduate and undergraduate students. And, finally, they have learned through trial and error the various ways in which they can use the multiple roles to best work with our campus writers-they have learned, and continue to learn, how to best redefine their roles.

Early on, Megan also discovered that training new consultants was a process of trial and error and thus began to see the need for writing center resources geared specifically toward such a mixed population of consultants. There are several reasons for this gap in the training literature. As mentioned, primary is the assumption that professional, faculty, and graduate student consultants are more experienced and need less training in their one-on-one work with students. Yet, our research and experiences as mentioned above-as well as the accounts from several of the authors included in this collection-show that this could not be further from the truth. Further, most writing center training manuals are rhetorically cast toward undergraduate peer consultants and do not necessarily address the particular dynamics of other types of consultants. Indeed, the emphasis on undergraduate peer tutoring in training manuals, including the challenges undergraduate peer consultants face and the reciprocal benefits they receive, has served to elide the presence of a distinctly different instructional dynamic encountered by professional, faculty, and graduate student consultants. At the time, in order to compose training materials that acknowledged such authority issues in her writing center, Megan gathered together materials that offered contextspecific advice in the Case Western Reserve University Writing Resource Center while simultaneously drawing from the well-established and incredibly useful handbooks already on the market, such as Leigh Ryan and Lisa Zimmerelli's (2016) Bedford Guide for Writing Tutors; Christina Murphy and Steve Sherwood's (2011) The St. Martin's Sourcebook for Writing Tutors; Shanti Bruce and Ben Rafoth's (2009) ESL Writers: A Guide for Writing Center Tutors; and various foundational essays by writing center scholars such as Muriel Harris on recognizing the various roles a tutor plays, and by Andrea Lunsford on negotiating a writing center session. 
While Megan still employs these materials, she also had to compose supplemental training materials for faculty and graduate consultants that address frequent nonundergraduate peer topics, like the fact that they are often older, teach their own classes, and occupy institutional leadership roles. Additionally, she queried and drew from The WCenter listerv, seeing it as an important "go-to" resource, making use of the collective knowledge of other writing center practitioners.

Joseph joined this project when he was hired to teach at Megan's institution while also serving as a faculty consultant in the writing center. During his two years working in the center, he became increasingly interested in how professional consultants occupy a unique institutional space on campus as well as a unique space in the field of writing center studies. He also noticed many of the same complex interactions between various groups of consultants that Megan experienced. Together, we published an article in WLN: A Journal of Writing Center Scholarship titled "Toward a Professional Consultant's Handbook: Researching Support and Training Methods" (Jewell and Cheatle 2016). In this work, we argue that professional consultants (in this case defined as nonundergraduate and graduate consultants) are often overlooked in training manuals because there is an assumption that they need less training than do undergraduate and graduate consultants. We identified a few key areas for professional consultants that need to be examined, including the tension of collaborator versus teacher, working with current and former students, maintaining professional boundaries with faculty in other disciplines, working with graduate students, working with faculty in a formal session, and professional development. We ended by citing the need for a guidebook, such as this, for consultants that are not necessarily undergraduate students.

While completing this initial study and publication for $W L N$, we also became interested in other consultants with unique situations, for example, faculty and graduate student consultants, that are not explicitly addressed in the peer tutor-training manuals that are most frequently directed toward undergraduate students. We see differences in these populations (professional, faculty, and graduate consultants) from undergraduate consultants in the areas of training, authority during consultations, mentoring, and professional development. Because of these issues, we believe that the time has come for a guide that not only draws upon these foundational texts but also recognizes the complex dynamics of nonpeer writing tutoring. The chapters we present here illustrate a fundamental first step in that process, and we are confident that they will generate even more conversations regarding writing 
centers in the coming years. In addition, our collection may be useful for centers employing undergraduate consultants because it attends to the important dynamics between different types of consultants. We have included eighteen chapters representing public and private, large and small, and four- and two-year US and one international institution; furthermore, authors include administrators, faculty consultants, professional consultants, and graduate consultants.

\section{FACULTY AND PROFESSIONAL CONSULTANTS}

As was previously noted, chapters on faculty and professional consultants have been combined in this part because of the significant overlap regarding issues encountered between these two populations. Chapters in this part were written by a diverse group of authors representing large and small institutions, public and private schools, four-year institutions and community colleges, online and in-person centers; chapters also cover a wide variety of subjects relevant to professional and faculty consultants. And while the chapters cover a wide range of topics, they broadly encompass training and the unique issues facing professional and faculty consultants.

\section{Faculty and Professional Consultant Training}

Four chapters provide training ideas and plans for faculty and professional consultants. In "Redefining Training for Faculty Tutors," chapter 1, Miriam E. Laufer explores the common misconception that faculty tutors need less training than peer tutors or even no training at all, an idea that is emphasized throughout chapters in this essay regarding nonpeer consultants. Drawing on her experience training faculty consultants at a community college, Laufer points out the areas of peer tutoring that may be applicable for faculty members while noting that specialized training for faculty consultants can leverage the existing knowledge of faculty consultants to create a professional learning community. In "Modular Training for Professional Writing Center Consultants," chapter 2, Fallon N. Allison uses her experience as a director of a community college writing center to design a series of online modules for training professional consultants. Because time and resources are an issue for professional consultant training, Allison uses online training to deploy and organize training modules based on the needs of the consultants. Through this process, Allison helps professional consultants enter the discourse community of the writing center 
while navigating the logistical hurdles that face administrators who want to provide training for professional consultants. Anne Shiell, in chapter 3, "Examining Assumptions about Training and Development for Writing Center Professional Consultants," challenges the assumption that professional consultants don't need training. Like Allison, she created modular trainings that are flexible and address the changing needs of professional consultants at her online writing center. As she notes, institutional human resources onboarding is often insufficient for writing centers; therefore, her additional training focuses on helping introduce professional consultants to the institutional knowledge of the center. This training, according to Shiell, results in increased staff engagement and retention. Chapter 4, Irina Ruppo's "Reading between the Lines: Professional Tutor Training with the Stanislavski System for Actors," provides an international perspective on writing centers. Managing a center in Ireland, Ruppo draws on the work of Constantin Stanislavski (the renowned theater practitioner) to create a series of training exercises for consultants designed to encourage empathetic engagement with texts and negotiating graduate/ undergraduate authority issues during consultations; her essay engages current theories on directive tutoring and can be used in various training situations. Together, these four chapters provide a number of approaches to training professional and faculty consultants that can be used by other centers or can be used to inform other writing centers' practices. And while specific chapters may focus on faculty or professional consultants, we believe that the training models and ideas function for both groups of consultants and represent worthwhile avenues for exploration.

\section{Faculty and Professional Consultant Identities, Roles, and Authority}

Four chapters address the identities, roles, and authority of faculty and professional consultants in writing centers and within institutional contexts. Chapter 5, Kimberly Fahle Peck et al.'s "Professional Tutors, Shifting Identities: Narratives from the Center," provides first-person narrative accounts of the personal lives of professional tutors. Fahle Peck et al. focus on the plural careerist identities of professional consultants and how those careers inform each other; they look at what skills each bring from previous (or other) careers as well as how these other careers inform their identities as professional consultants. Arundhati Sanyal and Kelly A. Shea, in chapter 6, "Teachers vs. Tutors: Is There a Place for Faculty Tutors in a University Writing Center," examine the 
difficulties faculty face when taking on the persona of a tutor. Through a survey of faculty consultants representing a range of academic ranks and disciplines, Sanyal and Shea determined that faculty consultants view themselves as distinct and different from peer consultants. Drawing on these surveys, Sanyal and Shea found that faculty consultants must negotiate their role with students during consultations while resisting the expectation of authority. Matthew Sharkey-Smith's chapter 7, "Between Definitions: Negotiating the Role of Professional Writing Consultants Online," provides valuable insight into what he depicts as the liminal institutional status of professional consultants who are, indeed, inseparable from their status. He discusses his own experiences and advocates a perspective whereby professional consultants' dual statuses are "sites of opportunities" while sharing his experiences in an online consulting model. Finally, Catherine Siemann's "Faculty and Professional Tutors, the Writing Center, and STEM," chapter 8, addresses professional and faculty consultants working at primarily science, technology, engineering, and mathematics (STEM) institutions. Siemann advocates that professional and faculty consultants serve as "expert outsiders" during consultations in order to leverage their extensive-often classroom-experience. She further draws on Andrea Lunsford's notion of the Burkean Parlor to emphasize shared power and control as well as collaboration. As Siemann notes, this model functions particularly well at STEM institutions because it is difficult to recruit peer tutors. By addressing different identities, roles, and authority for professional and faculty consultants, these chapters are relevant to administrators and other consultants alike because they underscore the lived experiences of professional and faculty consultants performing labor in writing centers; furthermore, the voices of such consultants strongly illuminate the critical issues regarding the writing center work that they address.

\section{GRADUATE STUDENT CONSULTANTS}

In the part on graduate consultants, there are ten chapters by both current graduate consultants, former graduate consultants, and administrators who work with graduate consultants. These chapters fall into four broad categories: training, authority during consultations, mentoring, and professional development. While the topics could apply to undergraduate, professional, or faculty consultants, they are geared specifically to graduate consultants and, as such, represent concerns that may be unique for them. 


\section{Authority}

Two chapters focus primarily on graduate consultant authority during consultations. Marcus Weakley and Mark Pedretti's chapter, "When Is a Peer Not a Peer? Negotiating Authority and Expertise in Graduate Student Writing Consultations," chapter 9, examines the power dynamics that occur between graduate consultants and graduate clients. While looking at a writing center at a graduate-only university, Claremont, in Southern California, the authors focus on the importance of content knowledge, versus general knowledge, in consultations between graduate students. They also discuss different types of trainings and strategies to address this issue of content disparity. Another work that focuses on authority between graduate consultants and graduate clients is Elise Dixon and Cassie Brownell's work "(Graduate) Friends with Benefits: Writing Relationships into the Center," chapter 13. Their work examines standing appointments, specifically the experiences of standing appointments between Dixon (the consultant) and Cassie (the client). As Dixon and Brownell point out, there are some in writing center studies who believe standing appointments run counterintuitively to the grand narrative that writing centers are there to help the writer, not just the writing; and, as such, there is a concern that standing appointments could become a crutch for clients who rely too much on one specific tutor. The authors argue that these standing appointments, rather than function as something negative, can help support a sustainable relationship and promote growth for graduate clients working with graduate consultants. In tracing their own unique experiences, Dixon and Brownell argue that standing appointments can result in co-mentoring, networking, and a sustained relationship that goes beyond the center.

\section{Training}

Four works included in this collection focus on training for graduate consultants. Elizabeth Festa, in "Genre Knowledge and (Cross)Disciplinary Awareness: Preparing Graduate Consultants to Support Proposals," chapter 17, explores how to best support graduate students writing proposals across a wide variety of disciplines at Rice University's writing center. Festa engages in the specialist-versus-generalist consultant debate, advocating for teaching graduate consultants the specific genre of proposal writing. In order to develop training modules for the National Science Foundation (NSF) Graduate Fellowship program, they collaborated with the institution's Graduate and Postdoctoral Studies Office. This training ensured that all graduate consultants 
could work on proposals, specifically those from the NSF Graduate Fellowship program. Megan Boeshart Burelle and Meagan Thompson, in "An Inquiry-Based Approach for Customizing Training for Graduate Student Tutors," chapter 18, reimagine graduate consultant training at their writing center that is staffed only by graduate consultants. Using an inquiry-based approach, they developed a set of heuristic questions that help position administrators to prepare graduate consultants to negotiate their role as consultants in the center, teach consulting practices, and encourage collaboration. Vicki Behrens and Alex Funt, in "Investing in Graduate Tutor Training: A Sustained Approach," chapter 15, trace the development of a training plan for graduate consultants at the University of North Carolina at Chapel Hill Writing Center. Because it is more comprehensive than an orientation or a workshop, and continues throughout the academic year, they term this training "onboarding." This onboarding focuses on feedback and reflection, graduate consultant involvement in administration, and building community to create a more engaged staff. Graduate consultants, termed "coaches," have a wide array of activities (e.g., peer coaching, feedback, and reflection) to help integrate them into the center and create a sense of community. Similar to Behrens and Funt, Joseph Cheatle and Genie Giaimo view training as onboarding because it is ongoing throughout the academic year. Their work, "Integrating Graduate Student Consultants: Community Building in Writing Centers through Onboarding and Mentorship," find that brief presemester orientations are not sufficient to create a positive and effective workplace culture. Rather, through a yearlong onboarding process, they examine how onboarding can be more engaging while welcoming graduate consultants into the professional writing center community.

\section{Professional Development}

Two works focus on professional development for graduate consultants. Kristin Messuri, in "Graduate Writing Center: A Professional Development Framework for Graduate Consultants from Diverse Fields," chapter 16, reconceptualizes the generalist-versus-specialist debate for graduate consultants at the Texas Tech University Writing Center to promote professional development. Messuri positions the specialist knowledge of individual graduate students as a benefit for the center; graduate consultants leverage their home disciplines to explain disciplinary conventions to other graduate consultants as well as create rhetorical reading guides for training. Establishing graduate students as "experts" 
in their own discourses provides them professionalization opportunities as they introduce their discipline's values, writing, and pedagogy. This work also serves to introduce graduate consultants to the field of writing center studies as they become disciplinary ambassadors for the center. Meanwhile, Rebecca Nowacek, Matt Burchanoski, Danielle Clapham, Will Fitzsimmons, Alex Frissell, Lisa Lamson, and Anna Scanlon's work "Graduate Tutor Professional Development—and Leadership-in an Undergraduate Writing Center," chapter 12, provides a program for professional development drawn from Marquette University's Ott Memorial Writing Center. The authors highlight the importance of introducing graduate students to the center and collaborative project opportunities. The result of their program is that graduate consultants feel welcomed into the community of writing center practice while helping to sustain the culture of the center.

\section{Mentoring}

Three works explore mentoring, a high-impact practice in higher education, for graduate consultants in writing centers. Joseph Cheatle and Genie Giaimo, in "Integrating Graduate Student Consultants: Community Building in Writing Centers through Onboarding and Mentorship," chapter 10, examine a peer-mentoring program for graduate consultants. This mentoring model is needed, they argue, because graduate students have different training than undergraduate students; undergraduate students often take a required course or extended training that is not always required of graduate students. As Cheatle and Giaimo demonstrate, there are positive outcomes for both mentors and mentees, and because graduate students come from various disciplines and departments, a mentoring program can be an effective way to create an inclusive environment and community. Anna Sicari, in chapter 11, "Critical Mentorship in the Writing Center: Teaching Intentional Kindness and Rhetoric of Respect in Staff Education," argues for the important role writing centers play in the academic experience of graduate consultants. Sicari writes that administrators should be mentoring graduate consultants in intentional kindness and the rhetoric of respect. Through this type of mentoring, modeling, and teaching, Sicari focuses on the human aspect of the center and the people working in it. Last, Alex Wulff's "Making the Invisible Visible: Valuing Labor in the Design of an Observation-Based Mentor Program for Graduate Student Writing Tutors," chapter 14, discusses the creation of a mentoring program, including observations and assessment rubrics for that program. He also 
argues for the importance of making labor visible in writing centers, specifically for graduate consultants, that compensates them for the work they provide through activities like mentoring.

Taken together, the two parts of our handbook addressing nonpeer consultants work not only to identify various groups of consultants, but to illustrate the rich interactions happening every day in US writing centers and abroad. Indeed, we hope that by sharing the voices of those involved in professional, faculty, and graduate staffed centers, we can both (a) broaden the idea of a writing center as an undergraduate-forundergraduate center and (b) underscore the critical problem-solving that takes place, often "on-the-spot," among staff in any given session. Further, we hope to shed light on the many situations encountered daily by writing center administrators working in multistaffed centers, from assisting consultants navigating interpersonal dynamics in sessions, to conducting staff meetings and trainings to address all staffing concerns, to representing the expertise of all consultants to their campus communities, including to those responsible for funding. Our collection makes clear how many writing center professionals engage daily in complex, critical work and, we hope, opens the door to more dialogue on the roles our consultants play. We see our Redefining of the roles as the first important step in acknowledging the dynamics of nonpeer tutoring, and we certainly hope that it is not the last.

\section{REFERENCES}

Bruce, Shanti, and Ben Rafoth, eds. 2009. ESL Writers: A Guide for Writing Center Tutors. Plymouth, NH: Boynton/Cook Publishers.

Jewell, Megan, and Joseph Cheatle. 2016. "Toward a Professional Consultant's Handbook: Researching Support and Training Methods." WLN: A Journal of Writing Center Scholarship 41 (3-4): 10-17.

McKinney, Jackie Grutsch. 2013. Peripheral Visions for Writing Centers. Logan: Utah State University Press.

Murphy, Christina, and Steve Sherwood. 2011. The St. Martin's Sourcebook for Writing Tutors. Boston, MA: Bedford / St. Martin's.

Ryan, Leigh, and Lisa Zimmerelli. 2016. Bedford Guide for Writing Tutors. Boston: Bedford / St. Martin's.

"Writing Centers Research Project Survey." n.d. Purdue Online Writing Lab. https://owl .purdue.edu/research/usability/owl_uxd_research.html. 